\title{
Application of Alkaline Solution by a Nebulizer, Rotahaler and Inhaler in Prevention of Spread of Covid-19
}

\author{
Dr. Indranil Chakraborty ${ }^{\star, \dagger}$
}

Pathologist of Kalna Sub-Divisional and Super-Speciality Hospital, West Bengal, India

ODOI: https://doi.org/10.15520/jcmro.v3i05.289

Accepted 06-05-2020; Received 09-04-2020; Publish Online 08-05-2020

\section{Reviewed By: \\ Dr. K. Daniel \\ Department: \\ Reviewer/CMRO

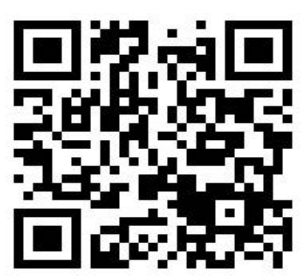

\begin{abstract}
The emergence of SARS-CoV-2 is the third introduction of a highly pathogenic coronavirus into the human population after the severe acute respiratory syndrome coronavirus (SARS-COV) and the Middle East respiratory syndrome coronavirus (MERSCOV). Even after taking thousands of human lives, there is no effective curative treatment till date. This virus infects human body by means of aerosol, droplets and contact. Mucous membrane mainly respiratory epithelium is the point of entry in case of SARS-COV2. Then it fuses with the pneumocytes and macrophages of respiratory epithelium by a complex protein-protein interaction. And this initial vital process of fusion needs acidic micro-environment. Here I propose a novel therapeutic approach that can prevent the entry of the virus into host cell and thus will curb down the infection rate and its severity significantly. Moderate alkaline solution of sodium bicarbonate will be used by a nebulizer, rotahaler or inhaler to the respiratory tract to make the airway surface fluid alkaline from acidic and this will hinder the entry of virus to host cells.
\end{abstract}

\section{BACKGROUND INFORMATION:}

Corona virus disease 2019 (COVID-19) is an infectious disease caused by severe acute respiratory syndrome corona virus 2 (SARS-CoV-2) with aerosol, droplets and contact as the main means of transmission .From the appearance of first case in wuhan, China in December,2019, it has now become a pandemic. Every country is facing the challenge of this menace now as covid-19 has a high secondary attack rate. So it needs an effective preventive and curative measure. Respiratory tract of an infected person is the main source of infection. SARS-COV-2 are enveloped positivestranded RNA viruses that replicate in the cytoplasm. For successful infection they need to deliver their nucleocapsid into the host cell for which they rely on the fusion of their envelope with the host cell membrane by a complex protein-protein interaction that demands a low $\mathrm{pH}$ status in respiratory epithelium [1, 2]. A $70 \mathrm{~kg}$ human would possess $26 \mathrm{ml}$ of lining fluid in the lung (LLF) [3]. Normally $\mathrm{pH}$ of LLF lies within a mildly alkaline range of 7.5-8.2 [4].

* Corresponding author.

† Email: indra258@gmail.com

\section{OBJECTIVES:}

i) Addressing the significance of $\mathrm{pH}$ change in fusion of SARS-COV2 viral envelope to host cell membrane.

ii) Identification of the effect of increasing $\mathrm{pH}$ in respiratory epithelium.

iii) Evaluating the infectivity of COVID -19 patients by swab collection from nasopharynx and oropharynx after alkaline solution treatment.

\section{HYPOTHESIS:}

The emergence of SARS-CoV-2 is the third introduction of a highly pathogenic coronavirus into the human population after the severe acute respiratory syndrome coronavirus (SARS-COV) and the Middle East respiratory syndrome coronavirus (MERS-COV). Main access of the virus is through respiratory epithelium by a complex host-virus interaction that eventually result into the entry of the virus into cytoplasm of pneumocytes and macrophages predominantly $[1,2]$. And is first step of infectivity is found to occur in acidic microenvironment according to studies. Here I propose the use of alkaline solution ( $\mathrm{pH}$ 9-11) through an inhaler or nebulizer and this will effectively disturb the $\mathrm{pH}$ of the local micro-environment, which will be enough to resist viral fusion with host cell. This Alkaline solution is 
composed of particles of Sodium bicarbonate [3-5] . Now with the application of alkaline solution $(\mathrm{pH} 9-11)$ over the airway surface fluid through rotahaler, inhaler and nebulizer, this viral entry can be halted significantly. This will in turn decrease the viral infectivity and will also decrease the viral load in airways that can be coughed or sneezed or talked out by the patient of COVID-19. With this approach we can interfere with the main three probable reasons of higher infectivity of SARS-COV-2 than its other two counterparts (SARS-COV AND MERS-COV) and those are, a) higher viral load in upper respiratory tract, b) infectivity by asymptomatic patients and, c) more chance of viability of SARS-COV2 on different surfaces and in aerosol that leads to its increased infectivity [6-9]. Use of rotahaler, inhaler, containing alkaline solution in convalescents and in general population of low risk category can be done to reduce the emergence of new cases.

\section{REVIEW OF LITERATURE:}

Coronavirus disease 2019 (COVID-19) is an infectious disease caused by severe acute respiratory syndrome coronavirus 2 (SARS-CoV-2) with droplets and contact as the main means of transmission. Immune function is a strong defense against invasive pathogens and there is currently no specific antiviral drug against the virus [10]. The spike (S) protein of coronaviruses facilitates viral entry into target cells. Entry depends on binding of the surface unit, S1, of the S protein to a cellular receptor, which facilitates viral attachment to the surface of target cells. In addition, entry requires $\mathrm{S}$ protein priming by cellular proteases, which entails $\mathrm{S}$ protein cleavage at the $\mathrm{S} 1 / \mathrm{S} 2$ and the $\mathrm{S} 2$ ' site and allows fusion of viral and cellular membranes, a process driven by the S2 subunit [1]. Belouzard, Sandrine et al. discusses coronavirus entry mechanisms focusing on the different triggers used by coronaviruses to initiate the conformational change of the S protein: receptor binding, low $\mathrm{pH}$ exposure and proteolytic activation [2]. Davis, Michael D. et al. showed that the inhalation of alkalinized buffer would measurably alkalinize the airways without compromising lung function or causing adverse events [4]. Eschenbacher, William L. et al. concluded that no change in vital lung function was clinically or statistically significant after inhalation of relatively high concentrations of alkaline aerosol by subjects with mild asthma and also it does not result in bronchoconstriction [5].

\section{RESEARCH PLAN:}

Sodium bicarbonate will be used as main ingredient. Application will be thorough rotahaler, inhaler and nebulizer..

1. Selection of patient: a) Any symptomatic and asymptomatic COVID-19 positive patient. b) High risk category people.

2. Sample size: 15 new patients (alkaline solution will be applied)

3. Control: 15 patients (sterile water will be applied)
4. Alkaline solution making: Ampoules of sodium bicarbonate that are readily available in market and tablet of sodium bicarbonate that can be dissolved in distilled water.

5. Dosage: $10 \mathrm{ml}$ of alkaline solution of $\mathrm{pH} 10.2$, will be given through nebulizer (keeping the target $\mathrm{pH}$ of airway surface fluid around 9). Repeat the same every 4 hours for 2 days.

6. Repeat testing after alkaline therapy: On second day swab collection from nasopharynx and oropharynx will be done for viral positivity. RT-PCR will be done for testing.

7. Concern over side effects: There is very little chance of adverse effects as sodium bicarbonate is compatible to human physiology. Also there are many established application of sodium bicarbonate in medical field.

8. Use of nebulizer: Admitted patients

9 Use of rotahaler and inhaler: Use depends on result of nebulizer. If positive and encouraging results obtained in nebulizer then general use in non-admitted persons will be performed.

\section{EXPECTED OUTCOME:}

i) Marked decrease in infectivity of asymptomatic and symptomatic COVID-19 positive patients with possible early cure and uneventful disease course.

ii) Use of this therapy in convalescent patients will reduce the chance of re-infection and will curb down the secondary wave of COVID-19.

iii) Possible general use of rotahaler and inhaler in low risk group of people as a major preventive measure.

\section{CONCLUSION:}

Each passing day is adding to the toll of new cases and death in India and worldwide. As there is no vaccine or curative therapy yet, main focus should be on restricting the secondary attack rate which is the main reason behind the rapid spread of COVID-19. In this scenario I propose the use of this novel therapy that can make a substantial difference in emergence of new cases and perhaps cure in early stages.

\section{REFERENCES}

[1] Van Doremalen N, Bushmaker T, Morris DH, Holbrook MG Gamble A, Williamson BN, et al. Aerosol and Surface Stability of SARS-CoV-2 as Compared with SARS-CoV-1. New England Journal of Medicine. 2020;382(16):1564-1567. Available from: https://dx.doi.org/10.1056/nejmc2004973.

[2] Lin L, Lu L, Cao W, Li T. Hypothesis for potential pathogenesis of SARS-CoV-2 infection--a review of immune changes in patients with viral pneumonia. Emerging Microbes \& Infections. 2020 Mar 23(just-accepted):1-4.

[3]

Hoffmann M, Kleine-Weber H, Schroeder S, Krüger N, Herrler T, Erichsen S, et al. SARS-CoV-2 Cell Entry De-pends on ACE2 and TMPRSS2 and Is Blocked by a Clin-ically Proven Protease Inhibitor. Cell. 2020;181(2):271-280.e8. Available from: https://dx.doi.org/10.1016/j.cell.2020.02.052 
[4] Belouzard S, Millet JK, Licitra BN, Whittaker GR. Mechanisms of Coronavirus Cell Entry Mediated by the Viral Spike Protein. Viruses. 2012;4(6):1011-1033. Available from: https://dx.doi.org/10.3390/v4061011.

[5] Fröhlich E, Mercuri A, Wu S, Salar-Behzadi S. Measurements of Deposition, Lung Surface Area and Lung Fluid for Simulation of Inhaled Compounds. Frontiers in Pharmacology. 2016;7:181-181. Available from: https://dx.doi.org/10. 3389/fphar.2016.00181.

[6] Fischer H, Widdicombe JH. Mechanisms of Acid and Base Secretion by the Airway Epithelium. Springer Science and Business Media LLC; 2006. Available from: https://dx.doi. org/10.1007/s00232-006-0861-0.

[7] Zou L, Ruan F, Huang M, Liang L, Huang H, Hong Z, et al. SARS-CoV-2 viral load in upper respiratory specimens of infected patients. New England Journal of Medicine. 2020;382(12):1177-1186.

[8] Davis MD, Walsh BK, Dwyer ST, Combs C, Vehse N, PagetBrown A, et al.. Safety of an Alkalinizing Buffer Designed for Inhaled Medications in Humans. Daedalus Enterprises; 2013. Available from: https://dx.doi.org/10.4187/respcare. 01753.

[9] Rothan HA, Byrareddy SN. The epidemiology and pathogenesis of coronavirus disease (COVID-19) outbreak. Journal of Autoimmunity. 2020;109:102433-102433. Available from: https://dx.doi.org/10.1016/j.jaut.2020.102433.

[10] Eschenbacher WL, Gross KB, Muench SP, and TLC. Inhalation of an Alkaline Aerosol by Subjects with Mild Asthma Does Not Result in Bronchoconstriction. American Thoracic Society; 1991. Available from: https://dx.doi.org/10. 1164/ajrccm/143.2.341. 